\title{
Genome-wide expression analysis of therapy-resistant tumors reveals SPARC as a novel target for cancer therapy
}

\author{
Isabella T. Tai, ${ }^{1,2}$ Meiru Dai, ${ }^{2}$ David A. Owen, ${ }^{3}$ and Lan Bo Chen² \\ 1Division of Gastroenterology, University of British Columbia, and Genome Sciences Centre, British Columbia Cancer Agency, Vancouver, \\ British Columbia, Canada. 'Department of Cancer Biology, Dana Farber Cancer Institute, Harvard Medical School, Boston, Massachusetts, USA. \\ ${ }^{3}$ Department of Pathology, University of British Columbia, Vancouver, British Columbia, Canada.
}

\begin{abstract}
Overcoming resistance to chemotherapy and radiation therapy has been a difficult but important goal in the effort to cure cancer. We used gene-expression microarrays to identify differentially expressed genes involved in colorectal cancer resistance to chemotherapy and identified secreted protein, acidic and rich in cysteine (osteonectin) (SPARC) as a putative resistance-reversal gene by demonstrating low SPARC expression in refractory human MIP101 colon cancer cells. We were able to achieve restoration of their radiosensitivity and sensitivity to 5-fluorouracil and irinotecan by reexpression of SPARC in tumor xenografts. Moreover, treatment of mice with SPARC conferred increased sensitivity to chemotherapy and led to significant regression of xenografted tumors. The results show that modulation of SPARC expression affects colorectal cancer sensitivity to radiation and chemotherapy. SPARC-based gene or protein therapy may ameliorate the emergence of resistant clones and eradicate existing refractory clones and offers a novel approach to treating cancer.
\end{abstract}

\section{Introduction}

Treatment failure due to chemotherapy resistance accounts for the high mortality rates in cancer. Many factors contribute to the initial intrinsic resistance to therapy. In colorectal cancer, not only is there constitutive expression of multidrug resistance genes MDR1 and MRP, but genetic mutations that are acquired in the multistep progression toward tumorigenesis also contribute to drug resistance. For example, mutations in p53, found in $50-60 \%$ of colorectal cancers; loss of DNA mismatch repair genes, found in hereditary nonpolyposis colorectal cancer (1); and mutations in $\mathrm{K}$-ras have all been associated with poor response, higher relapse rates, and increased mortality (2-5). Mutations in genes involved in cell cycle regulation, such as p21 and $\mathrm{p} 27$, have been shown to protect tumors from undergoing apoptosis elicited by various anticancer agents (6). Subsequent exposure to chemotherapy leads to a clonal expansion of cancer cells that have acquired additional genetic alterations that further promote therapy resistance. There is upregulation of thymidylate synthase (7-9) and dihydropyrimidine dehydrogenase expression $(10,11)$ following exposure to 5 -fluorouracil $(5-\mathrm{FU})$, which contributes to therapy resistance to this drug. The recent introduction of irinotecan (CPT-11) and oxaliplatin in combination with 5-FU for the treatment of stage IV colorectal cancer has significantly improved response rates from $10 \%$ to $40-50 \%$ $(12,13)$. Yet emergence of resistance to CPT-11 as a result of upregulation of an ATP-binding cassette family member, ABCG2 (14), or to oxaliplatin as a result of upregulation of ERCC1 (15) has now been observed.

Nonstandard abbreviations used: CIS, cisplatin; CPT-11, irinotecan;

5-FU, 5-fluorouracil; ETO, etoposide; MIP/SP, MIP101 cells overexpressing SPARC; rSPARC, recombinant SPARC; SPARC, secreted protein, acidic and rich in cysteine (osteonectin).

Conflict of interest: The authors have declared that no conflict of interest exists.

Citation for this article: J. Clin. Invest. 115:1492-1502 (2005).

doi:10.1172/JCI23002.
The multiplicity of genetic alterations involved in the development of chemotherapy resistance supports a high-throughput genomics approach to identify various key genetic changes that contribute to this phenomenon. In this genomics approach, we used oligonucleotide microarrays to identify differentially expressed genes in colorectal cancer cells resistant to 5-FU, CPT-11, cisplatin (CIS), and etoposide (ETO). Here, we report on the identification of secreted protein, acidic and rich in cysteine (osteonectin) (SPARC) as a putative therapy resistance reversal gene whose expression was significantly decreased in resistant colorectal cancer cells. SPARC belongs to a growing family of extracellular proteins called matricellular proteins. Based on sequence homology, several members of this family have been identified, such as hevin, SC1, QR-1, follistatin-like proteins (TSC-36), and testican. Since its identification and cloning, several important biological functions have been attributed to SPARC. Its high evolutionary conservation suggests an important physiological role for this protein $(16,17)$. Initial studies showed that SPARC was important in bone mineralization (18). Its role has been expanded to include tissue remodeling (19), endothelial cell migration $(20,21)$, morphogenesis $(19,22,23)$, and angiogenesis $(24,25)$. SPARC has also been shown to have an antiproliferative effect on endothelial cells, mesangial cells, fibroblasts, and smooth muscle cells (26-28). There is growing evidence for its role in malignancy, as variable expression of SPARC has been linked to cancer progression in a number of tumors (29-32). Many of the biological functions attributed to SPARC in primary cells have been similarly noted in association with its role in tumorigenesis. For example, SPARC's well-known role in inhibiting cell growth in primary cells has been noted in gliomas, where SPARC has been shown to delay tumor growth in vivo $(31,33)$. In ovarian cancer, lower SPARC expression is noted in advanced tumors (30), and studies using SPARC -/- $^{-}$animals reveal that loss of SPARC enhances growth of tumor xenografts of pancreatic and lung cancers $(34,35)$. Its inhibitory effect on 

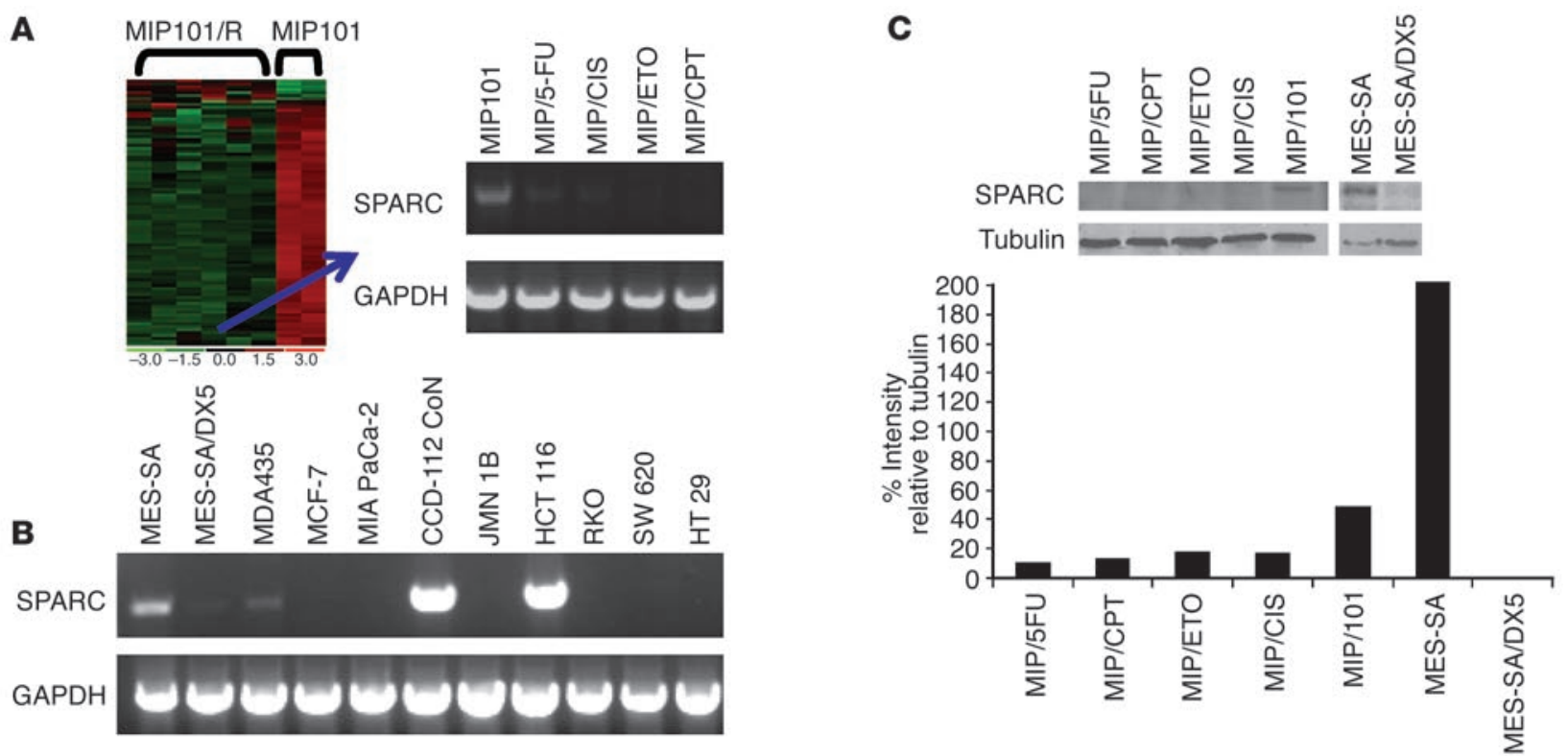

\section{Figure 1}

Human SPARC mRNA and protein levels in cell lines sensitive and resistant to chemotherapy. (A) The oligonucleotide microarray result was confirmed by semiquantitative RT-PCR. MIP101/R, resistant MIP101 cells. (B) SPARC mRNA expression in cancer cell lines (paired sensitive and resistant uterine sarcoma MES-SA and MES-SA/DX5; breast cancer MDA435 and MCF-7; pancreatic MIA PaCa-2; normal colon CCD-112 CoN; mesothelioma JMN 1B; and colorectal HCT 116, RKO, SW620, and HT29). (C) Protein levels in sensitive MIP101 and resistant cells (MIP/5FU, MIP/CPT, MIP/ETO, MIP/CIS) and another pair of sensitive and resistant cells (MES-SA and MES-SA/DX5).

angiogenesis has been demonstrated in the slower growth rate of neuroblastomas in vivo (33). Moreover, SPARC's ability to induce apoptosis has been shown not only in ovarian cancers, where overexpression of SPARC leads to apoptosis (30), but also in pancreatic cancer cells implanted in wild-type SPARC ${ }^{+/+}$animals (35). These studies support SPARC's role in tumorigenesis, and the results reported here provide evidence of a novel function for SPARC as a sensitizer to chemotherapy and radiation therapy and its potential usefulness in gene- and protein-based therapies aimed at promoting treatment response in cancer.

\section{Results}

SPARC $m R N A$ and protein levels are low in tumors resistant to chemotherapy. Resistant MIP101 cells were developed following long-term incubation with incremental concentrations of 5-FU, CPT-11, CIS, and ETO. There was at least an 8-fold increase in drug $\mathrm{IC}_{50}$ in all resistant cell lines for each of the respective agents. Cross-resistance to other agents was indicated by a 2 -fold increase in $\mathrm{IC}_{50}$. Human genome U95Av2 GeneChip arrays (Affymetrix) were used to probe for differentially expressed genes between sensitive and resistant MIP101 cells. SPARC stood out as being consistently underexpressed by 12.9-fold in all 4 resistant cell lines. This was supported by significantly lower mRNA levels of SPARC in the MIP101 cell lines resistant to 5-FU, CPT-11, ETO, and CIS (MIP/5FU, MIP/CPT, MIP/ETO, and MIP/CIS) by semiquantitative RT-PCR compared with the sensitive parental cell line (Figure 1A). This decrease in SPARC gene expression did not appear to be unique to this particular set of resistant MIP101 cell lines, as semiquantitative RT-PCR revealed that a well-established uterine sarcoma cell line, MES-SA, also showed decreased expression of SPARC mRNA when it was resistant to a different chemotherapeutic agent, doxorubicin (MES-SA/DX5) (Figure 1B).
In the case of cell lines of other epithelial origin, breast cancer cell line MDA435 had slightly higher levels of SPARC expression than did MCF-7; no expression was detected in pancreatic cancer cell line MIA PaCa-2, mesothelioma cell line JMN 1B, or colorectal cancer cell lines RKO, SW 620, and HT 29; and high levels of SPARC expression were detected in normal colon cell line CCD-112 CoN and colon cancer cell line HCT 116.

There was also correlation between gene expression/protein levels of SPARC and development of resistance (Figure 1C). Not only was there a significant decrease in SPARC protein in all resistant MIP101 cells, but this pattern was also reflected in the uterine sarcoma cell line pair (MES-SA, MES-SA/DX5), where cells resistant to doxorubicin (MES-SA/DX5) also had significantly lower levels of SPARC.

In normal human colon, SPARC protein expression was highest in the colonic epithelium (Figure 2, A and B). In the submucosal layer, SPARC was also noted in the endothelial cells (Figure 2A inset). SPARC expression levels were reduced following malignant transformation, and they decreased in colorectal adenocarcinoma irrespective of the disease stage (Figure 2, $\mathrm{B}$ and $\mathrm{C}$ ). This was even more evident in a histological sample containing both a focus of malignancy and normal colonic epithelium: higher SPARC expression was evident in the normal colonic epithelium (Figure 2B, boxed region) compared with the malignant epithelium (Figure 2B, arrows). Furthermore, SPARC levels decreased in therapy-refractory colorectal adenocarcinomas that recurred in patients following chemotherapy with 5-FU/ leucovorin (Figure 2, E and G) compared with the original therapy-naive primary tumor (Figure 2, D and F).

Human SPARC in vitro sensitizes colorectal cancer cells to chemotherapy. There appeared to be a differential pattern of expression of SPARC in cancer cell lines, with the development of resistance, 


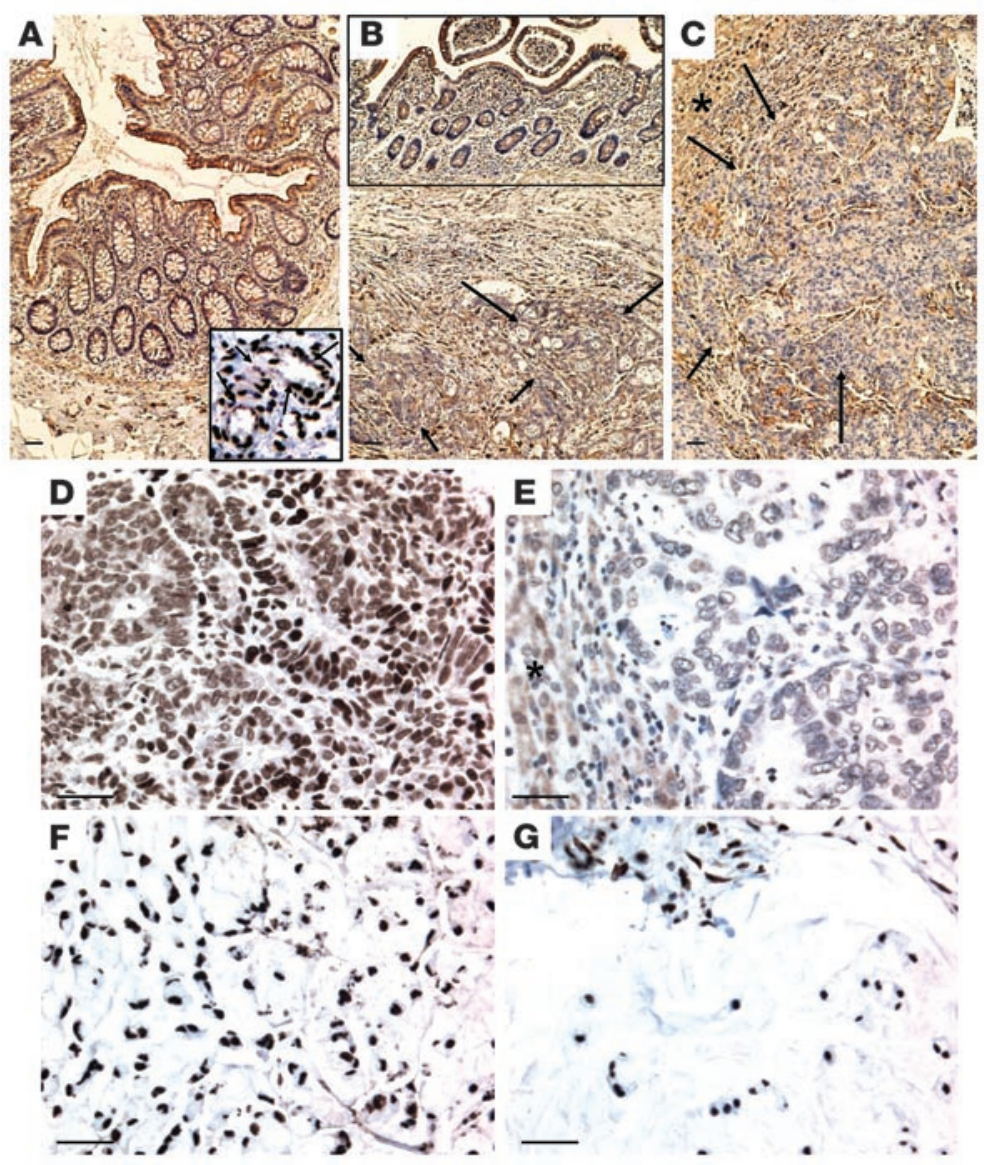

Figure 2

SPARC expression in human colonic epithelium. Normal colon shows SPARC expression in normal colonic epithelium (A and boxed area in $\mathbf{B}$ ), and endothelia cells in the submucosa (A, inset). SPARC levels are lower in colorectal adenocarcinomas (arrows) at primary sites (B) and following metastasis to liver ( $\left(^{*}\right)(\mathbf{C})$. Lower expression was also observed in paired human colorectal cancers (patient $\mathbf{A}$ : $\mathbf{D}$ and $\mathbf{E}$; patient B: $\mathbf{F}$ and $\mathbf{G}$ ) following treatment with 5-FU/leucovorin ( $\mathbf{E}$ and $\mathbf{G}$ ) compared with the untreated primary tumor (D and F). Sections, $6 \mu \mathrm{m}$; scale bars: $20 \mu \mathrm{m}$.

at both the mRNA and protein levels. To investigate the possible role of SPARC deficiency in chemotherapy resistance, we explored the effect of SPARC. In vitro results indicated that MIP101 cells resistant to 5-FU (MIP/5FU) did not undergo apoptosis upon treatment with $500 \mu \mathrm{M}$ of 5-FU (Figure 3A), whereas a significant number of cells from the parental, 5-FU-sensitive cell line underwent apoptosis following exposure to a similar concentration of 5-FU for 12 hours (Figure $3 \mathrm{~A}$ ). Incubation of MIP/5FU with $5 \mu \mathrm{g} / \mathrm{ml}$ SPARC for 24 hours followed by a 12-hour exposure to $500 \mu \mathrm{M} 5$-FU reversed the resistant phenotype, and conferred sensitivity of these cells to 5-FU, as apoptotic cells were once again detected by TUNEL assay (Figure 3A). Incubation with $5 \mu \mathrm{g} / \mathrm{ml}$ exogenous SPARC alone without subsequent exposure to chemotherapy did not induce apoptosis in either the parental MIP101 (data not shown) or MIP/5FU cells (Figure 3A). A similar reversal in resistance was observed when other resistant MIP101 clones (MIP/CPT, MIP/ETO, MIP/CIS) were exposed to SPARC followed by chemotherapy (data not shown).

Based on the above results, it appeared that SPARC may influence chemosensitivity of cancer cells. In order to test this hypothesis, we generated MIP101 cells overexpressing SPARC (MIP/SP) and used them for subsequent in vitro and in vivo studies. Several of the MIP/SP clones showed greater expression and secretion of SPARC relative to control MIP/Zeo cells (MIP101 cell lines stably transfected with a negative expression empty vector) (Figure 3B). The sensitivity of MIP/SP cells to various chemotherapies was assessed by colonyforming assay (Figure $3 \mathrm{C}$ ). The results revealed that overexpression of SPARC conferred increased sensitivity to chemotherapy, as fewer colonies of MIP/SP cells formed at similar concentrations of chemotherapy compared with MIP/Zeo cells (Figure 3C). Similarly, there appeared to be a significantly greater proportion of MIP/SP cells undergoing apoptosis following a 12-hour exposure to either 1,000 $\mu \mathrm{M}$ 5-FU, $100 \mu \mathrm{M}$ CIS, or $200 \mu \mathrm{M}$ CPT-11 compared with control MIP/Zeo according to FACS analysis of annexin V-labeled cells (Figure 3D). In fact, while only $7.6 \% \pm 0.2 \% \mathrm{MIP} / \mathrm{Zeo}$ cells were detected to be apoptotic following incubation with CIS, this proportion increased to $31.1 \% \pm 5.8 \%$ with the overexpression of SPARC $(P=0.02)$ MIP/SP cells were similarly sensitive to 5 -FU (MIP/Zeo, $10.4 \% \pm 2.3 \%$ apoptosis vs. MIP/SP, $25.1 \% \pm 2.7 \%$ apoptosis; $P=0.002)$ and CPT-11 (MIP/Zeo, $8.5 \% \pm 1.6 \%$ vs. MIP/SP, $26.3 \% \pm 3.0 \% ; P=0.003)$ but not to ETO (MIP/Zeo, $11.1 \% \pm 0.5 \%$ vs. MIP/SP, $21.3 \% \pm 7.8 \% ; P=0.15$ ). This increased sensitivity of MIP/SP cells to 5 -FU is also reflected in a significantly greater activation of caspase- 3 and cleavage of its downstream target $\alpha$-fodrin compared with control MIP/Zeo (Figure $3 \mathrm{E}$ ).

Overexpression of SPARC appeared to confer increased sensitivity of MIP101 colon cancer cells to chemotherapy in vitro by activating apoptosis. This overexpression also modified the progression of cells through the cell cycle. Cell cycle analysis of MIP/SP cells showed a delay in the progression of cells through $\mathrm{G}_{1} /$ $S$ phase (Figure 4 and Table 1). At 2 hours after release from cell cycle synchronization, $13.9 \%$ of MIP/Zeo cells had alreadyentered the $\mathrm{G}_{2} / \mathrm{M}$ phase, while no MIP/SP cells had reached this phase. By 4 hours, only 25.1\% MIP/Zeo cells remained in S phase and $61.8 \%$ of the cells had already progressed to $\mathrm{G}_{2} / \mathrm{M}$ phase, while $46.5 \% \mathrm{MIP} / \mathrm{SP}$ cells remained in $\mathrm{S}$ phase and only $45.5 \%$ had entered $\mathrm{G}_{2} / \mathrm{M}$ phase. Exposure to 5 -FU resulted in cell cycle arrest at $\mathrm{G}_{1} / \mathrm{S}$ phase for both $\mathrm{MIP} / \mathrm{Zeo}$ and MIP/SP cells (Figure 4 and Table 1).

Overexpression of SPARC increases the sensitivity of colon cancer cells to chemotherapy and radiation therapy in vivo. Given the results of the in vitro data, we next attempted to determine whether the resistant phenotype could be reversed in vivo using tumor xenograft mouse models. Following implantation of SPARCoverexpressing MIP/SP cells and exposure to 3 cycles (of a total of 6) of either 5-FU or CPT-11, 50\% of the animals showed complete tumor regression (Figure 5, A-D). The remaining chemotherapy-treated animals implanted with MIP/SP cells also had dramatic reductions in tumor size compared with animals implanted with MIP/Zeo cells. All control MIP/Zeo and untreated MIP/SP animal xenografts had tumors larger than $400 \mathrm{~mm}^{2}$ by 50 days following the initiation of chemotherapy treatment, while chemotherapy-treated animals implanted with MIP/SP 

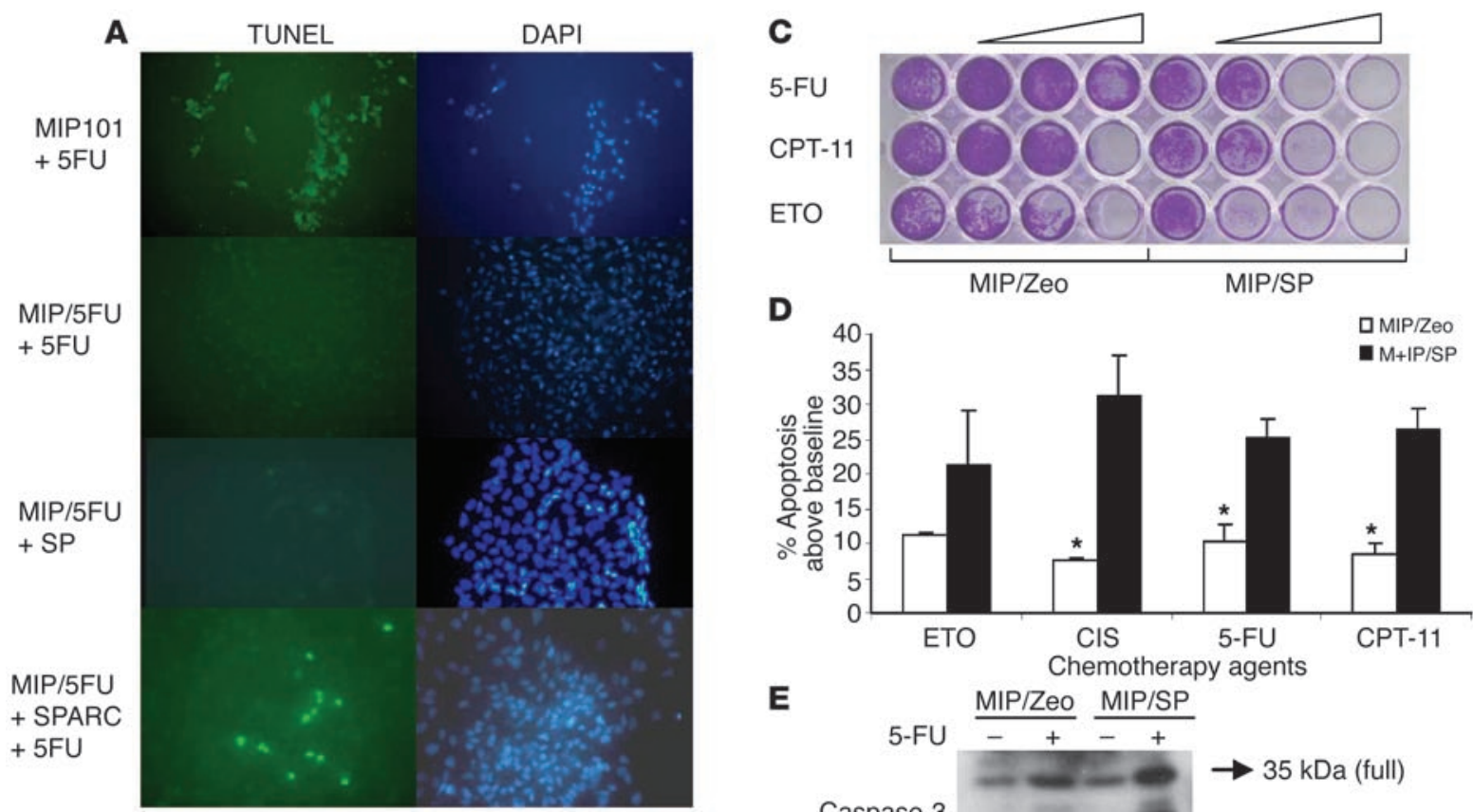

$\mathbf{E}$

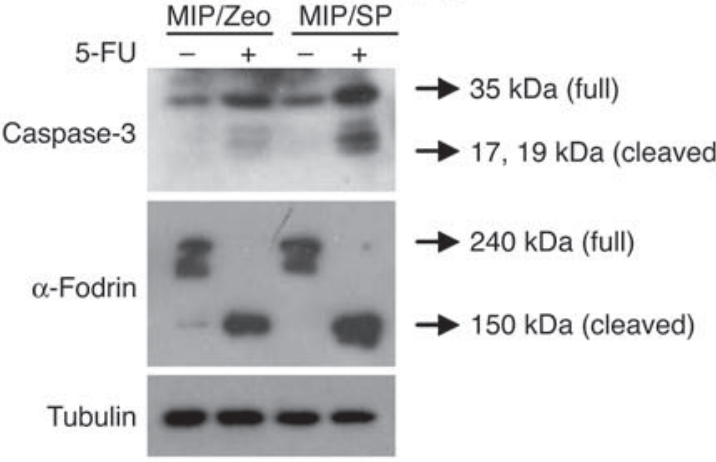

\section{Figure 3}

SPARC alters the sensitivity of MIP101 colorectal cancer cells to chemotherapy. (A) TUNEL assay shows the effect of exogenous SPARC on apoptosis in MIP/5FU cells. (B) Levels of SPARC secreted by MIP/SP cells (clones c1, c2, and c3) compared with control MIP/Zeo cells and following concentration of the incubation media (conc, c2-conc). (C) Colony-forming assay of MIP/SP and control MIP/Zeo cell lines following exposure to incremental concentrations of 5-FU, CPT-11, or ETO. (D) Sensitivity of MIP/SP compared with MIP/Zeo cells to chemotherapy (FACS analysis of annexin V-labeled cells). ${ }^{*} P<0.05$, Student's $t$ test; $n=3$ different experiments. (E) Immunoblots of MIP/Zeo and MIP/SP cells exposed to $500 \mu M$ 5 -FU for 12 hours and probed for caspase-3 and $\alpha$-fodrin.

either had complete tumor regression by day 60 of treatment, and those tumors that remained were smaller than $300 \mathrm{~mm}^{2}$ at 140 days after initiation of chemotherapy.

Overexpression of SPARC in MIP/SP not only increased the sensitivity of these cells to chemotherapy but also conferred increased sensitivity to radiation therapy (Figure 5E). A significantly greater number of animals implanted with MIP/SP cells had complete tumor regression following a single dose of radiation (100 Gy) than those with control xenografts of MIP/Zeo cell lines. As early as 4 weeks after initiation of radiation therapy, $30 \%$ of MIP/SP xenografts had complete tumor regression, and by 15 weeks of radiation therapy, there was complete regression in all MIP/SP xenograft animals, while $30 \%$ of MIP/Zeo (control) xenografts continued to harbor tumors $(P=0.02$ after 3 weeks of radiation therapy; standard 2-sample $t$ test).

Serum obtained from animals with MIP/SP xenografts showed significantly greater levels of SPARC than that obtained from mice with xenografts of MIP/Zeo cells (Figure 5F), which thereby confirmed the sustained overexpression and secretion of SPARC in this animal model.
Exogenous SPARC potentiates the effect of chemotherapy in xenograft animal models via various routes of administration. The ability of SPARC to confer increased sensitivity to both chemotherapy and radiation therapy appeared to be supported by the MIP/SP overexpression system. However, initial in vitro studies also indicated that exogenous exposure to the protein itself was sufficient to induce apoptosis in resistant MIP101 cell lines at concentrations of chemotherapy agents that were previously ineffective in these cells. Therefore, we tested the ability of exogenous SPARC to increase sensitivity to chemotherapy in vivo using xenograft tumor models. Intraperitoneal injections of SPARC(s), a concentrated supernate containing SPARC, in combination with 5 -FU showed a significant reduction in tumor size by 65 days after treatment (Figure 6A), with evidence of complete tumor regression in $83 \%$ of animals receiving this combination therapy by 76 days after treatment, while none of the other treatment groups became tumor free. Similar results were obtained when SPARC(s) was injected via a subcutaneous route, as significantly smaller tumors were observed following combination treatment with 5-FU 
Table 1

Effect of SPARC on cell cycle progression

\begin{tabular}{|c|c|c|c|c|c|c|}
\hline Phase of cell cycle & & ItEI & ase & sy' & nizatio & \\
\hline$G_{1}$ phase & $\mathrm{Oh}$ & $2 \mathrm{~h}$ & $4 \mathrm{~h}$ & $6 \mathrm{~h}$ & $8 \mathrm{~h}$ & $10 \mathrm{~h}$ \\
\hline MIP/Zeo & $43.4^{\mathrm{A}}$ & 12.5 & 13.1 & 17.5 & 13.2 & 29.2 \\
\hline & 53.3 & 10 & & & & 3.7 \\
\hline Zep + 5FU & 21.8 & 27 & 2 & 26. & 25 & 29.3 \\
\hline & 33.4 & 20. & & & 2.0 & -0 \\
\hline S phase & $\mathrm{Oh}$ & $2 \mathrm{~h}$ & & $6 \mathrm{~h}$ & $8 \mathrm{~h}$ & 10 \\
\hline MIP/Zeo & 57.6 & 73.7 & & 34 & 8.4 & 2.6 \\
\hline 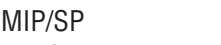 & 46.7 & 87.1 & & 13 & 14.3 & 5.4 \\
\hline MIPO/Zep + 5FU & 76 & 62.4 & 63.9 & 66.1 & 67.7 & 66. \\
\hline $\mathrm{MIP} / \mathrm{SP}+5 \mathrm{FU}$ & 65.3 & 69.1 & 73.4 & 72.4 & 75.2 & 66. \\
\hline $\mathrm{G}_{2} / \mathrm{M}$ phase & $\mathrm{Oh}$ & $2 \mathrm{~h}$ & $\mathrm{~h}$ & $6 \mathrm{~h}$ & $8 \mathrm{~h}$ & $10 \mathrm{~h}$ \\
\hline MIP/Zeo & 0 & 13.9 & 61 & 79 & 78.5 & 68 \\
\hline MIP/SP & 0 & 0 & & 74.8 & 75.7 & 70. \\
\hline MIPO/Zep & 2.23 & 10 & 10 & 7.8 & 6.4 & \\
\hline $\mathrm{MIP} / \mathrm{SP}+5 \mathrm{FU}$ & 1.33 & 7.78 & 5.8 & 5.1 & 0 & 6.8 \\
\hline
\end{tabular}

APercentage of cells in each phase of the cell cycle after release from synchronization. See Figure 4 for graphical representation of these results.

(data not shown). By 42 days after treatment, 66\% of animals showed complete tumor regression following exposure to the combination of subcutaneously injected SPARC(s) and 5-FU, while no tumor-free xenografts were evident in other experimental groups (Figure 6D).

However, given that the initial purpose of the investigation was to determine whether SPARC was capable of reversing the resistant phenotype, we also treated mice that were implanted with resistant MIP/5FU cells with subcutaneous SPARC(s) and intraperitoneal 5-FU in order to assess whether exogenous exposure of this protein could influence its response to 5-FU. While tumor xenografts from all animals continued to grow in the first 21 days of treatment (following cycle 1), thereafter, the combination of SPARC(s) and 5-FU resulted in significant tumor regression by 40 days after treatment, whereas treatment with 5-FU alone was ineffective in these 5-FU-resistant cells (MIP/5FU) (Figure 6C). By 117 days after treatment, complete tumor regression was observed in $80 \%$ of xenografts exposed to the combination treatment of SPARC(s) and 5-FU (Figure 6C). Results of subsequent studies utilizing purified recombinant SPARC (rSPARC) supported earlier observations that concomitant exposure to subcutaneous rSPARC and intraperitoneal 5-FU induced greater tumor regression than exposure to either rSPARC or 5-FU alone (Figure 7A).

Histological examination of tumors recovered from animals with xenografts of MIP101 cells revealed a significantly greater number of cells undergoing apoptosis upon treatment with SPARC(s) and 5-FU compared with either SPARC(s) or 5-FU alone (Figure 7B). No significant difference in cell proliferation, as detected by immunostaining for Ki-67 (Figure 8 and Figure 9A), was seen in tumor xenografts recovered from any of the treatment groups. However, fewer blood vessels were noted by immunostaining for CD34 in tumors recovered from SPARC(s)-treated animals, either alone or in combination with 5-FU (Figure 8 and Figure 9B), irrespective of the levels of VEGF, as these were similar in all treatment groups (data not shown). Evaluation of the treatment effect of SPARC on the ECMs of tumor xenografts did not reveal any significant differences in the expression of collagen IV or laminin within the tumor parenchyma between treatment groups (Figure 10); however, a thicker, fibrous band positively stained with laminin surrounding the tumor appeared to be more prominent in animals treated with SPARCs than in other treatment groups (Figure 10, arrows).

\section{Discussion}

SPARC has diverse roles in normal cells, many of which have been shown to contribute to tumorigenesis, yet its potential role in modulating chemotherapy sensitivity has not been explored. Here, we have been able to demonstrate that alterations in SPARC expression in vitro an in vivo change the sensitivity of colorectal MIP101 cells to radiation and chemotherapy by enhancing apoptosis in tumor cells and possibly also by modulating blood vessel formation in tumors.

It is generally accepted that aggressive cancers are often associated with poorly differentiated histopathology and poor prognosis, as reflected by their poor response to chemo- and radiation therapy. In the present study, the relative levels of SPARC expression in the normal human colonic epithelium decreased with malignant transformation, as indicated by its decrease in immunohistochemical staining for SPARC. Once tumors become refractory to therapy, there is a further decrease in SPARC expression, as noted in paired tumor samples obtained before and after chemotherapy. It is possible that this decrease in SPARC expression may contribute to the initial intrinsic refractoriness of colorectal cancers to treatment and a further decrease in SPARC potentiates therapy resistance that is often observed clinically (12). Indeed, this appears to be the case as levels of SPARC in ovarian cancers also appear to be inversely correlated with clinical stage (30).

The pattern of decreasing mRNA and protein expression with the development of resistance suggests that SPARC may
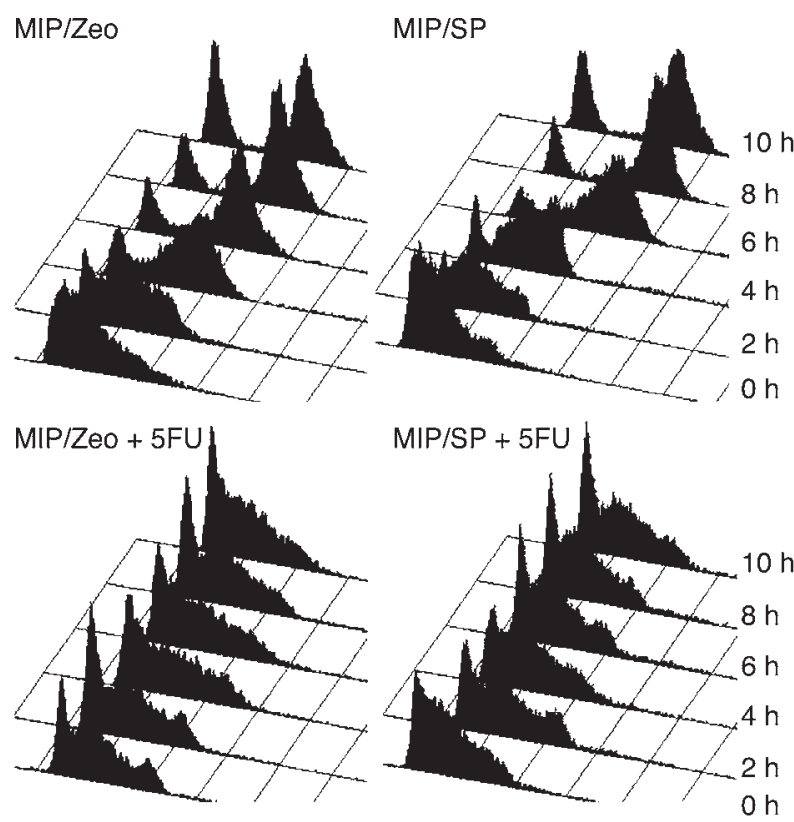

Figure 4

Effect of SPARC on cell cycle progression. There is a delay in the $\mathrm{G}_{1} /$ $S$ phase in MIP/SP cells compared with control MIP/Zeo cells. See Table 1 for quantitative results. 
A

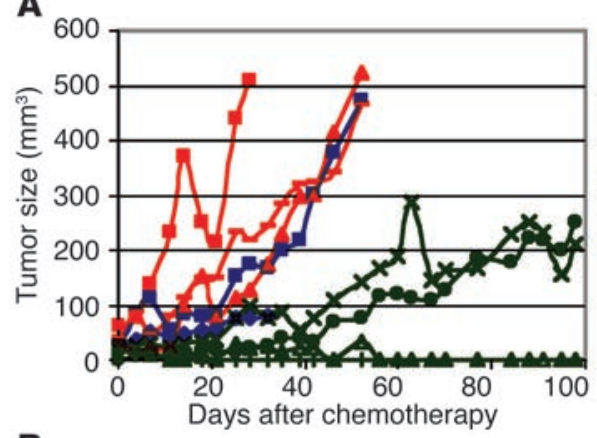

B

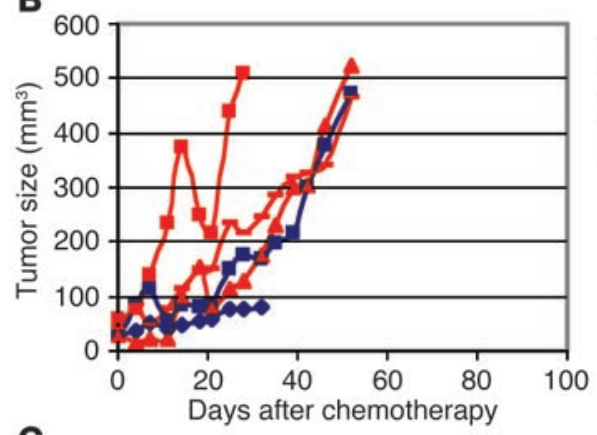

C

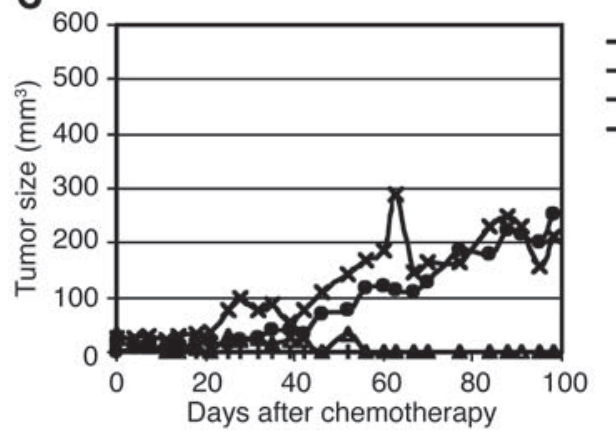

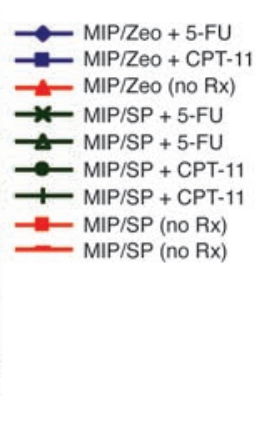

$\sim$ MIP/Zeo + 5-FU $\rightarrow-$ MIP/Zeo + CPT-11 - MIP/Zeo (no Rx) $\rightarrow$ MIP/SP (no Rx) - MIP/SP (no Rx)

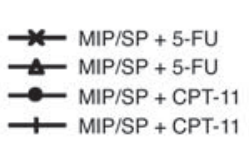

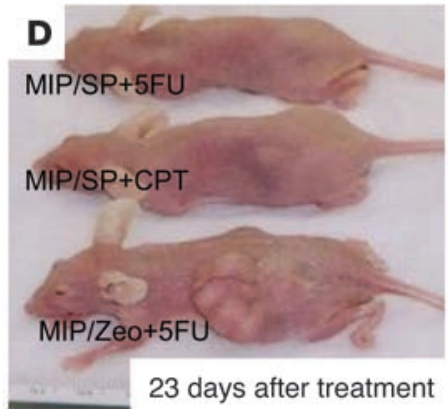

$\mathbf{E}_{110}$

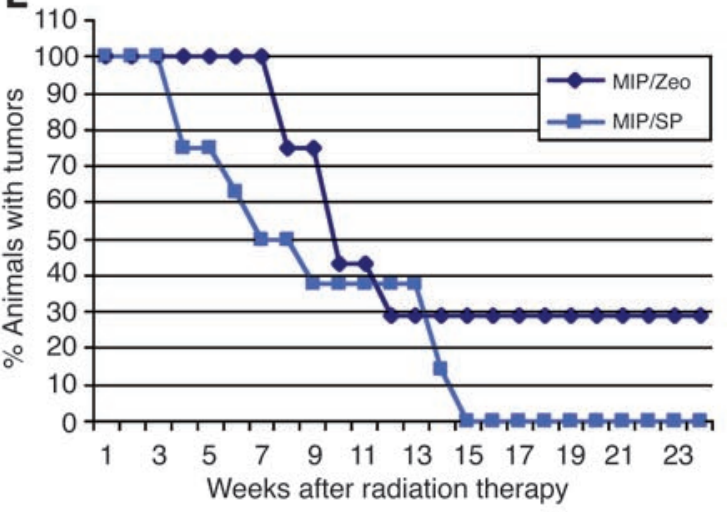

$\mathbf{F}$

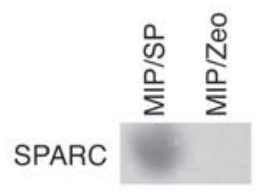

Figure 5

Effect of chemotherapy and radiation therapy on tumor xenografts of MIP/SP cells. (A) Tumor regression in MIP/SP tumor xenografts exposed to 5-FU or CPT-11 compared with MIP/Zeo cells. To allow better visualization of the results provided in A, data from control animals only (tumors of MIP/Zeo and nontreated MIP/SP xenografts) are shown in B, while data from all MIP/SP xenografts treated with 5-FU or CPT-11 are represented in C. (D) Representative MIP/Zeo or MIP/SP tumor xenografts following treatment with 2 cycles of 5-FU or CPT-11. (E) Effect of radiation therapy on MIP/SP tumor xenografts ( $n=10$ animals/group; total dose of radiation, 100 Gy, single dose; $P=0.02$ after 3 weeks of radiation; standard 2 -sample $t$ test). (F) SPARC levels in serum obtained from animals with xenografts of MIP/SP an MIP/Zeo 42 days after implantation.

play a role in determining sensitivity of tumors to chemo- and radiation therapy. This possibility was initially supported by in vitro TUNEL assays showing reversal of the chemoresistant phenotype following exogenous exposure to SPARC prior to treatment with chemotherapy at a dose that was previously incapable of inducing an apoptotic response. Similarly, MIP/SP cells overexpressing this protein had a stronger response to 3 chemotherapy drugs (5-FU, CIS, and CPT-11), with an increase in the number of cells undergoing apoptosis from less than $15 \%$ in the control MIP/Zeo cell line to as high as 31\% in the MIP/SP cell line. More importantly, this effect of SPARC in conferring increased sensitivity to chemotherapy held true in tumor xenograft models, where there was complete tumor regression in $50 \%$ of the animals implanted with the SPARC-overexpressing MIP/SP cells following treatment with 3 cycles of either 5-FU or CPT-11. Similarly, a single $100-$ Gy dose of radiation resulted not only in a more dramatic rate of tumor regression in MIP/SP tumor xenografts than in control animals but also in complete regression in all MIP/SP xenografts by 15 weeks after radiation therapy. In subsequent in vivo studies, treatment with exogenous SPARC combined with 5-FU dramatically improved tumor response to therapy, significantly increasing tumor regression. It is important to note that while xenografts of resistant MIP $/ 5 \mathrm{FU}$ tumors were unresponsive to 5-FU alone, the addition of SPARC to the 5-FU treatment regimen reversed the resistant phenotype and allowed the gradual regression of these tumors beginning on day 28 of treatment, which resulted in complete tumor regression in $80 \%$ of animals by 117 days of treatment. These results suggest a role for SPARC in conferring chemo- and radiosensitivity to tumors.

SPARC has been shown to inhibit the growth of primary normal cells, such as endothelial, fibroblast, mesangial, and smooth 

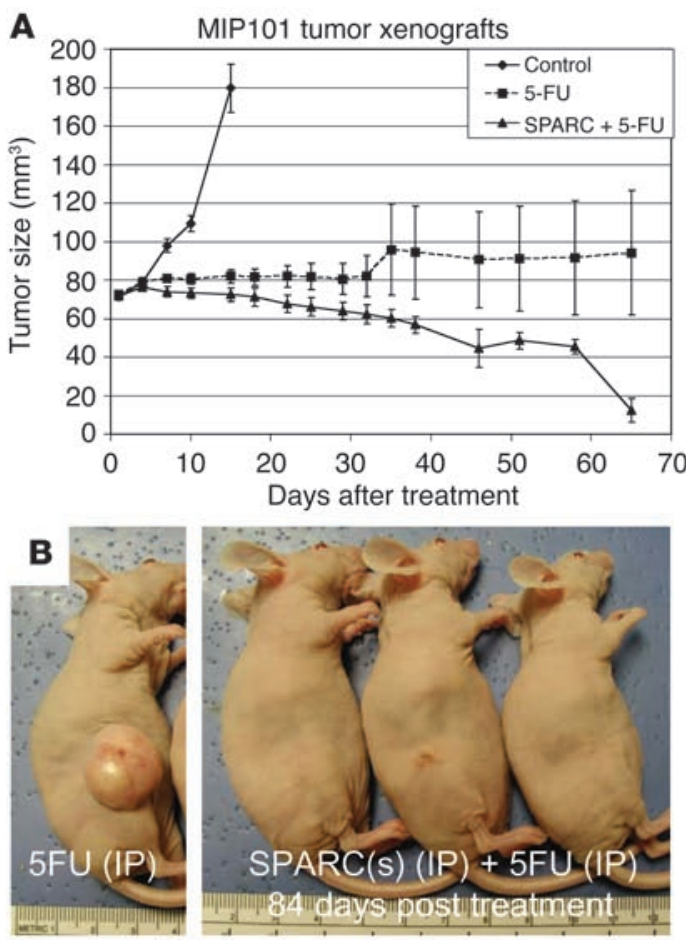
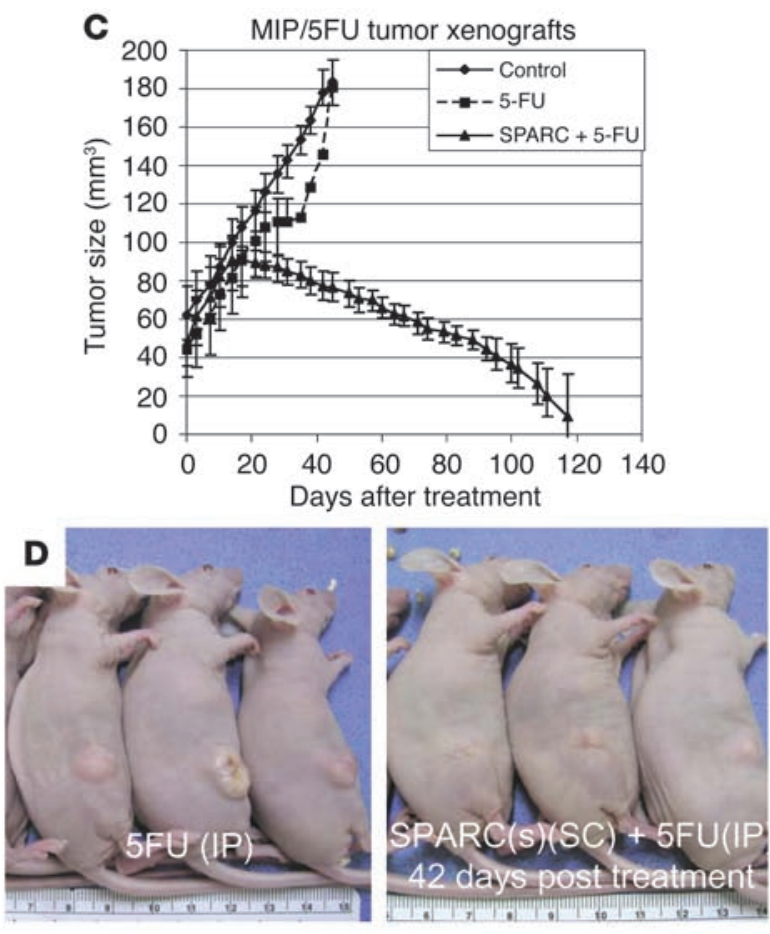

\section{Figure 6}

Effect of combination therapy with SPARC(s) and 5-FU on tumor regression. Exposure of MIP101 tumor xenografts to combination therapy consisting of intraperitoneal (IP) SPARC(s) and 5-FU ( $n=6$; mean \pm SE) (A and B) or subcutaneous (SC) SPARC(s) and 5-FU (results are representative of those obtained from 8 animals) (D). (C) Treatment of resistant MIP/5FU tumor xenografts with combination therapy with SPARC(S) $(n=6$ animals; mean \pm SE).

muscle cells, and this property may also contribute to its role in tumorigenesis, as lower levels of this protein would allow increased cell proliferation and tumor aggressiveness. The implication that loss of SPARC expression promotes tumor growth is supported by observations that it is downregulated following malignant transformation in ovarian cancers (30) and that upregulation of SPARC in these cells result in the development of nontumorigenic clones, while downregulation of SPARC results in more aggressive phenotypes (36). In Lewis lung cancer cells, exposure to SPARC was effective in inhibiting cell proliferation in vitro (34), which supported earlier studies that glioma cells overexpressing SPARC had delayed tumor growth in vivo (31). Studies have shown that SPARC causes cell cycle arrest at the $G_{1}$ phase in endothelial cells $(37,38)$, and our own studies revealed a delay in progression through the $G_{1} / S$ phase of the cell cycle in MIP/SP cells in vitro. However, exogenous exposure to SPARC in our tumor xenograft models had no effect on cell proliferation. These results are supported by similar observations of tumors grown in $\operatorname{SPARC}^{+/+}$mice $(34,35)$.

In addition to our observations showing enhancement of apoptosis in tumors exposed to SPARC and 5-FU, results of histological assessment of tumor xenografts also suggested that exposure to SPARC modulates blood vessel formation. SPARC can influence angiogenesis by inhibiting endothelial cell and fibroblast proliferation induced by VEGF, PDGF, and FGF $(21,24,39,40)$. Although blood vessels appeared to be decreased in SPARCtreated xenografts, this was not associated with any differences in VEGF expression in these tumors. This lack of association between blood vessel formation and VEGF expression was similarly noted in pancreatic cancer xenografts in SPARC ${ }^{+/+}$animals (35). Modulation of the tumor microenvironment by SPARC may be an important factor that influences the sensitivity of tumors to chemo- and radiation therapy, ultimately contributing to greater tumor regression in vivo.

Activation of apoptosis also appears to be an important mechanism by which SPARC promotes therapy sensitivity. Yiu and colleagues showed that exposure to exogenous SPARC alone was capable of inducing apoptosis in ovarian cancer cells (30). Studies with SPARC ${ }^{-/-}$mice showed enhanced pancreatic and lung tumor growth in these animals $(34,35)$, and a study in which tumors were implanted in $\mathrm{SPARC}^{+/+}$mice revealed higher numbers of caspase-3 and poly-ADP-ribose polymerase-positive (PARP-positive) cells. Although our current finding that exposure of MIP101 colorectal cancer cells to exogenous SPARC alone had no effect on apoptosis either in vitro or in vivo differs from these earlier observations, it supports the notion that SPARC can influence the induction of apoptosis in tumorigenesis. Indeed, exposure to SPARC appears to enhance the induction of apoptosis when tumor cells are concomitantly exposed to chemotherapy, which suggests that SPARC modulates the sensitivity of cancer cells to the effects of chemo- and radiation therapy but that by itself, it is unlikely to activate apoptosis. In human pathological specimens of ovarian tumors with high SPARC expression levels, there did not appear to be a significant increase in the number of apoptotic cells (30), which thereby supports our observations that SPARC alone is unlikely to 

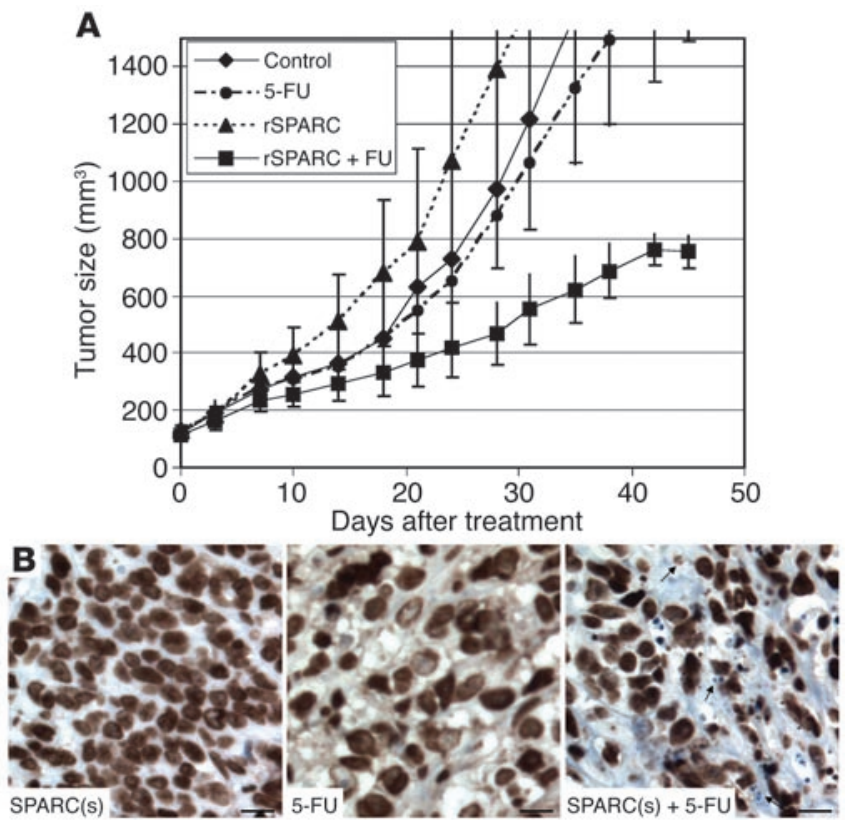

induce apoptosis. However, these differing observations of the effect of exogenous SPARC on apoptosis may reflect differences in animal models and cell- and tissue-specific differences in response. Indeed, SPARC likely promotes increased sensitivity to chemotherapy and radiation therapy by enhancing tumor cell apoptosis, and this is supported in our study by the following in vitro and in vivo observations: (a) there was a greater degree of activation of caspase- 3 and subsequent cleavage of $\alpha$-fodrin in cells overexpressing SPARC following exposure to chemotherapy in vitro; and (b) greater numbers of apoptotic cells were noted in tumor xenografts exposed to SPARC and 5-FU compared with SPARC alone.

Our current observations suggest a role for SPARC in potentiating the effects of chemotherapy and radiation to promote tumor regression. The mechanisms by which SPARC induces this effect appear to be multifactorial, and additional studies are required to delineate the intriguing observations presented here. Importantly, the results of the various mouse tumor xenograft models point to the possibility that SPARC-based gene and protein therapy can be used with current therapeutic modalities to affect tumor regression in advanced colorectal cancer refractory to therapy.

\section{Figure 7}

Effect of SPARC in combination with 5-FU on tumor regression and apoptosis. (A) Treatment of MIP101 tumor xenografts with purified recombinant SPARC in combination with $5-\mathrm{FU}(n=3$; mean \pm SE). (B) Tumors recovered from animal xenografts treated with SPARC(s) or 5-FU alone did not show increased numbers of apoptotic bodies (arrows) compared with tumors recovered from animals treated with a combination of SPARC(s) and 5-FU. Sections, $6 \mu \mathrm{m}$; scale bars: $15 \mu \mathrm{m}$.

\section{Methods}

Cell culture. The poorly differentiated human colorectal cancer cell line MIP101 (41) was maintained in DMEM supplemented with 10\% FBS, $1 \%$ penicillin/streptomycin (Invitrogen Corp.) at $37^{\circ} \mathrm{C}$ and $5 \% \mathrm{CO}_{2}$. Resistant MIP101 cells were developed following long-term incubation with incremental concentrations of 5-FU $(10-500 \mu \mathrm{M})$, CIS (1-100 $\mu \mathrm{M})$, ETO (0.1-5 $\mu \mathrm{M}$; Sigma-Aldrich), and CPT-11 (1-50 $\mu \mathrm{M}$; Pharmacia Corp.) over 3 months. MIP101 cells stably transduced with SPARC (MIP/SP) and its control (MIP/Zeo) were maintained in DMEM supplemented with $10 \% \mathrm{FBS}, 1 \%$ penicillin/streptomycin, and $0.01 \%$ Zeocin (Invitrogen Corp.) at $37^{\circ} \mathrm{C}$ and $5 \% \mathrm{CO}_{2}$.

Oligonucleotide microarray. Total mRNA from cells grown under similar culture conditions (70-75\% confluence, maintained in DMEM supplemented with $10 \%$ FBS and $1 \%$ penicillin/streptomycin) was extracted using Trizol reagent (Invitrogen Corp.). For each sample, $15 \mu \mathrm{g}$ of labeled cRNA (Enzo kit; Affymetrix) was hybridized to each duplicate Human Genome U95Av2 GeneChip Array (Affymetrix) and scanned using standard Affymetrix protocols and scanners. GeneChip images were captured using Affymetrix GeneChip software, and expression values for
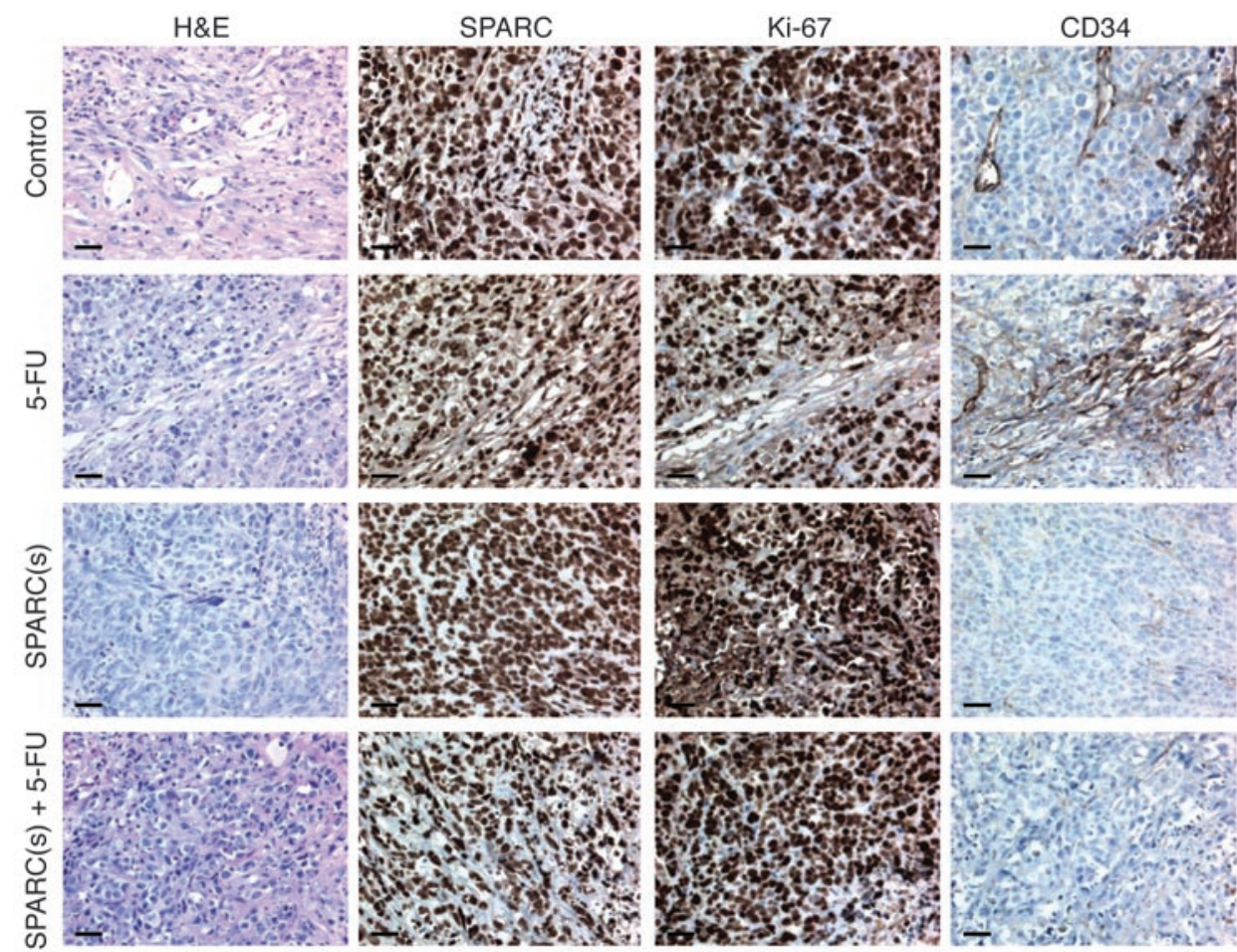

Figure 8

Evaluation of cell proliferation and blood vessel formation in tumor xenografts following treatment with SPARC(s) and 5-FU. Immunoperoxidase staining shows no significant difference in the levels of SPARC and no effect on cell proliferation (staining with Ki-67). Decreased staining with CD34 shows fewer blood vessels in SPARC(s)-treated animals. Sections, $6 \mu \mathrm{m}$; scale bars: $20 \mu \mathrm{m}$. 

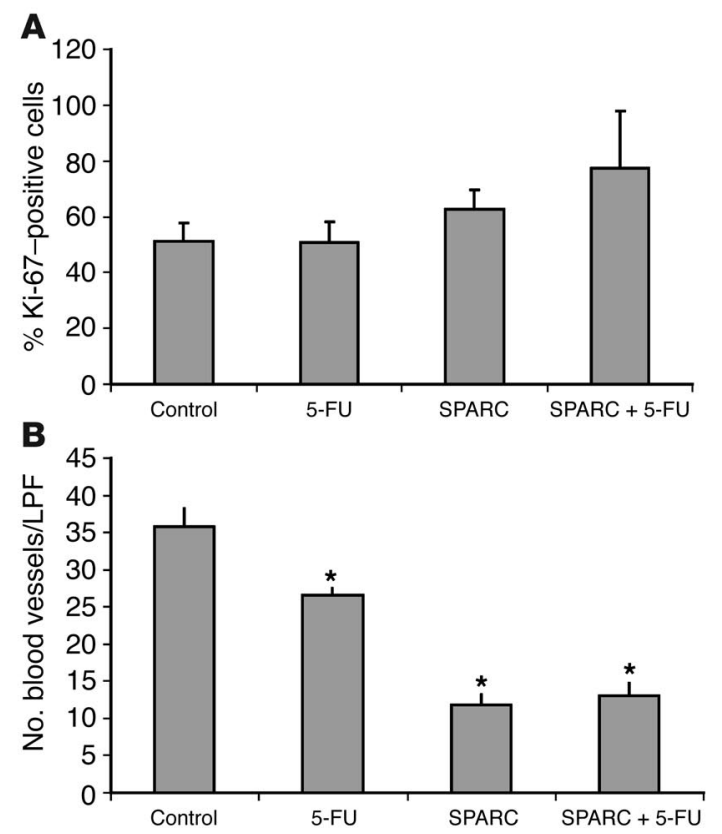

\section{Figure 9}

Evaluation of cell proliferation and blood vessel formation in tumor xenografts following treatment with SPARC(s) and 5-FU. (A) No significant differences were noted in $\mathrm{Ki}-67-$ positive nuclei in the xenografts harvested from various treatments. (B) As indicated by the lower numbers of CD34-positive blood vessels, significantly fewer blood vessels were noted in xenografts from animals treated with 5-FU compared with controls, but more significant is the further decrease in animals treated with SPARC alone or in combination with 5 -FU. ${ }^{*} P<0.05$, Student's $t$ test. LPF, low-power field.

each gene were calculated using a model-based expression algorithm (dChip v1.0) (42). Gene expression data were analyzed and filtered using the following criteria: (a) greater than 2-fold change in gene expression, (b) absolute expression difference greater than 100 , (c) $P \leq 0.05$ for testing experimental values equivalent to baseline, (d) presence call for each gene in more than $20 \%$ of samples; (e) $P \leq 0.05$, paired $t$ test.

Analytical RT-PCR. Total RNA was extracted from cultured cells, at $75 \%$ confluence and under similar culture conditions, using TRIZOL reagent. RT-PCR was performed using One-Step RT-PCR (BD Biosciences). SPARC-specific primers used were: 5'-CGAAGAGGAGGTGGTGGCGGAAA - 3' (sense) and 5'-GGTTGTTGTCCTCATCCCTCTCATAC-3' (antisense); GAPDH: 5'-CTCTCTGCTCCTCCTGTTCGACAG-3' (sense) and 5'AGGGGTCTTACTCCTTGGAGGCCA-3' (antisense). Reaction was set at: $50^{\circ} \mathrm{C}$ for 1 hour, followed by 45 cycles at $94^{\circ} \mathrm{C}$ for 1 minute, $65^{\circ} \mathrm{C}$ for 1 minute, $72^{\circ} \mathrm{C}$ for 2 minutes, and $72^{\circ} \mathrm{C}$ for 10 minutes. PCR products were separated on $1 \%$ agarose gel electrophoresis.

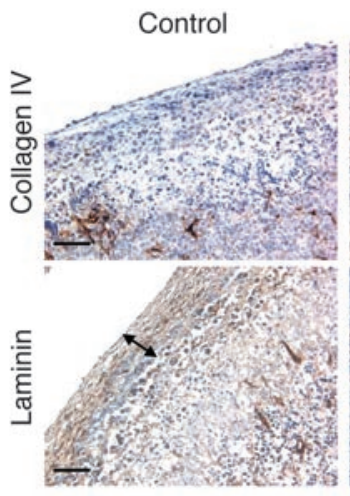

\section{Figure 10}

Detection of apoptosis. Cells undergoing apoptosis were fluorescently labeled by TUNEL assay. Cells undergoing exogenous exposure to SPARC were conditioned to serum-free medium VP-SFM (SFM) (supplemented with $4 \mathrm{mM}$ glutamine; Invitrogen Corp.) for 1 month prior to experimentation. Cells were then plated on glass coverslips and incubated with $5 \mu \mathrm{g} / \mathrm{ml}$ SPARC (Haematologic Technologies Inc.) for 24 hours, followed by a 12-hour exposure to either 1,000 $\mu \mathrm{M}$ 5-FU, $200 \mu \mathrm{M}$ CPT-11, $100 \mu \mathrm{M}$, CIS, or $10 \mu \mathrm{M}$ ETO and processed for labeling by an In Situ Cell Death Detection kit (Fluorescein; Promega). For quantitation of apoptosis, MIP/SP or MIP/Zeo cells seeded at 250,000 cells/plate were exposed to a 12-hour incubation with the drug concentrations noted above and processed for staining for annexin $\mathrm{V}$ and propidium iodide using an Apoptosis Detection Kit (R\&D Systems). The proportion of cells labeled with annexin $\mathrm{V}$ and propidium iodide was analyzed by the XL Flow Cytometer (Beckman Coulter Inc.). Data were collected from 100,000 events, and all experiments were performed in triplicate.

Transfection and selection of clone. The SPARC cDNA in pcDNA3.1 expression vector and a negative expression control vector (pcDNA3.1/Zeo) (Resgen GeneStorm Clone; Invitrogen Corp.) were used. Transfections were performed based on a modified protocol (43). Stable cells overexpressing SPARC (MIP/SP) were screened for SPARC mRNA expression by RT-PCR analysis. MIP/SP clones with the highest expression of SPARC mRNA (by RT-PCR) and secreted protein (by immunoblot analysis) were selected for subsequent in vitro and in vivo studies. Control cell lines used for this study included MIP101 cells stably transduced with pcDNA3.1/Zeo (MIP/Zeo) and were selected based on Zeocin resistance. For the determination of the amount of SPARC secreted, $2 \times 10^{6}$ cells were plated on $10-\mathrm{ml}$ plates in DMEM supplemented with $5 \%$ FBS, $1 \%$ penicillin/streptomycin for 24 hours. After 2 washes with serum-free conditioned media VP-SFM (Invitrogen Corp.), MIP/SP and MIP/Zeo cells were incubated with $10 \mathrm{ml}$ of VP-SFM for 24 hours. From each cell line, $5 \mathrm{ml}$ of the collected media was concentrated with Centricon Plus-20 (Millipore Corp.) to $500 \mu$ l. Twenty microliters of each sample were used for immunoblotting.

Characterization of the cell cycle in MIP/SP cells. MIP/Zeo and MIP/SP cells were seeded at 200,000 cells/6-well plates in DMEM (5\% FBS) and subjected to cell cycle synchronization with double thymidine block $(2 \mathrm{mM}$ thymidine [Sigma-Aldrich] in DMEM supplemented with $2 \%$ FBS). After the initial 16-hour thymidine block, cells were released in DMEM (FBS 10\%)
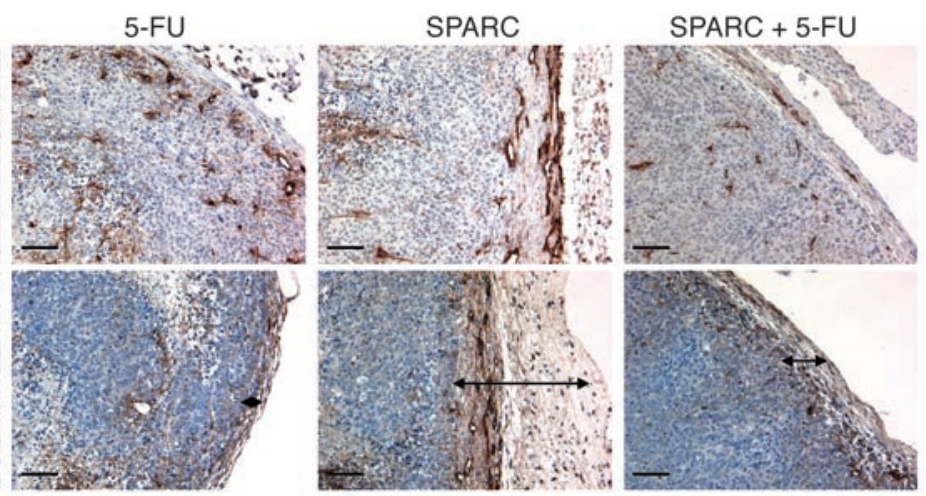

Assessment of the effect of SPARCs exposure on the ECM of tumor xenografts. Collagen IV is noted predominantly around blood vessels, and no significant differences in immunoperoxidase staining is seen in the ECMs between control and any of the treatment groups. Laminin expression in the ECM within the tumor xenograft is similarly unaffected in treatment groups, with its predominant expression noted within the fibrous capsule surrounding the graft. A thicker fibrous band (arrows) is noted surrounding xenografts of animals treated with SPARCs alone. 
for 12 hours, and this was followed by a second 14-hour thymidine block. Cells released from this block were collected at timed intervals and processed for cell cycle analysis: cells were fixed in $80 \%$ ethanol for $30 \mathrm{~min}$ utes on ice and then incubated with $2.5 \mu \mathrm{g} / \mathrm{ml}$ propidium iodide (SigmaAldrich) and $50 \mu \mathrm{g} / \mathrm{ml}$ RNase (Sigma-Aldrich) in PBS for 30 minutes at $37^{\circ} \mathrm{C}$ and analyzed by an XL Flow Cytometry Analyzer $(n=2)$.

Colony-forming assay. MIP/Zeo and MIP/SP cells at 1,000 cells/plate in 48-well plates were incubated with 5 -FU $(0 \mu \mathrm{M}, 10 \mu \mathrm{M}, 100 \mu \mathrm{M}$, or $1,000 \mu \mathrm{M})$, CPT-11 $(0 \mu \mathrm{M}, 1 \mu \mathrm{M}, 10 \mu \mathrm{M}$, or $100 \mu \mathrm{M})$, or ETO $(0 \mu \mathrm{M}, 10 \mu \mathrm{M}, 100 \mu \mathrm{M}$, or $1,000 \mu \mathrm{M})$ for 4 days. Cells were then washed with DMEM and incubated in fresh medium containing the appropriate concentrations of chemotherapy for an additional 7 days. Cells were stained with $0.2 \%$ crystal violet. The number of colonies formed in the treated group was calculated as a percentage of the colonies formed from the control, untreated cells.

Concentrated SPARC(s). MIP/SP cells plated at $1 \times 10^{6}$ cells in $100-\mathrm{cm}$ flasks in DMEM (10\% FBS, $1 \%$ penicillin/streptomycin, $0.1 \%$ Zeocin) for 24 hours were subsequently washed with PBS and incubated in serum-free VP-SFM medium (supplemented with $4 \mathrm{mM}$ glutamine) for 72 hours. This SPARC-containing supernatant was concentrated from $500 \mathrm{ml}$ to $2 \mathrm{ml}$ using Centricon Filter units (Millipore) at $4^{\circ} \mathrm{C}$ and subsequently used for animal studies. As a control, SFM was processed in a similar manner.

rSPARC production and purification for animal studies. SPARC cDNA was cloned into the BamHI and HindIII sites of the pBlueBacHis2 vector (pBlueBacHis2/SPARC), with positive clones confirmed by DNA sequencing. The $\mathrm{pBlueBacHis} 2 / \mathrm{SPARC}$ vector construct was transfected into Sf9 insect cells using a Bac-N-Blue Transfection Kit (Invitrogen Corp.) following the manufacturer's protocol. The recombinant Histagged SPARC protein was purified using His-Bind Quick columns (Novagen). Purified rSPARC was analyzed by fast protein liquid chromatography (FPLC; Pharmacia), which revealed a single peak at $43 \mathrm{kDa}$, confirming the purity of rSPARC used in the animal studies. The activity of purified rSPARC was verified by inhibition of cell proliferation (Cell Proliferation ELISA, BrdU; Boehringer Mannheim GmbH) as follows: MIP101 cells conditioned to serum-free medium VP-SFM (supplemented with $4 \mathrm{mM}$ glutamine) for 1 month prior to experimentation were plated in 96-well plates at 5,000 cells/well and incubated with increasing concentrations of rSPARC for 24 hours, followed by incubation with BrdU for 8 hours (unpublished data).

Animal studies. Tumor xenograft animal models were used to assess the effect of SPARC on tumor progression in vivo. For all studies, NIH Swiss nude mice ( 6 weeks old; Taconic) were implanted with $2 \times 10^{6}$ cells at the left flank, except in studies assessing the efficacy of rSPARC, where $3 \times 10^{6}$ cells were implanted. Treatment regimens were initiated once the average tumor size reached $75-100 \mathrm{~mm}^{3}$ in volume. Tumors were measured using a hand-held caliper (Fisher Scientific International Inc.) with concurrent body weight measurements until the completion of the study. Chemotherapy was provided using a 3-week cycle regimen ( 6 cycles): intraperitoneal injections of $25 \mathrm{mg} 5-\mathrm{FU} / \mathrm{kg}$ body weight or $25 \mathrm{mg} \mathrm{CPT}-11 / \mathrm{kg}$ body weight 3 times in week 1 of each cycle, followed by 2 weeks of treatment-free periods. The dosing schedule for SPARC(s) was $100 \mu \mathrm{l}$ of SPARC(s) (intraperitoneal or subcutaneous) or $100 \mu \mathrm{g} /$ animal rSPARC (subcutaneous) 3 times per week until the completion of the chemotherapy cycle. Control animals received saline or SFMs (only for in vivo studies wherein other treatment groups received SPARC[s]). Animals implanted with MIP/SP and $\mathrm{MIP} /$ Zeo tumor xenografts were irradiated with a single $100-$ Gy radiation dose (2,000 Ci Mark I 68A Cesium-137; JL Shepherd \& Associates). Serum samples were collected from animals with MIP/Zeo and MIP/SP tumor xenografts after the second cycle of chemotherapy treatment. In a separate study, animals with MIP101 tumor xenografts treated with 2 cycles of therapy had tumors harvested for histological evaluation following fixation in $10 \%$ formalin and routinely processed for immunohistochemistry, as described below. Experimental groups (2 animals/group) for this study included those treated with (a) subcutaneous SPARC(s); (b) SPARC(s) with 5-FU; (c) 5-FU; (d) subcutaneous SFM, and (e) saline. All studies were approved by the Animal Care and Use Committee at the Dana Farber Cancer Institute.

Protein extracts and immunoblots. Protein extracts and immunoblots were prepared as previously described (44). The following modifications were made. Total protein was extracted from cell lysates using CHAPS lysis buffer (50 mM Pipes/Hcl, pH 6.5; 2 mM EDTA; 0.1\% Chaps; $20 \mu \mathrm{g} / \mathrm{ml}$ Leupeptin; $10 \mu \mathrm{g} / \mathrm{ml}$ Pepstatin A; $10 \mu \mathrm{g} / \mathrm{ml}$ Aprotinin; $5 \mathrm{mM}$ DTT; $1 \mathrm{mM}$ PMSF). Antibodies to SPARC $(1 \mu \mathrm{g} / \mathrm{ml}$; Haematologic Technologies Inc.) and $\alpha$-tubulin $(0.2 \mu \mathrm{g} / \mathrm{ml}$; Sigma-Aldrich) were used. For the detection of SPARC in serum samples of animal xenografts of MIP/SP and MIP/Zeo cells, $250 \mu \mathrm{g}$ of total protein from each sample was incubated with mouse anti-human SPARC antibody (Haematologic Technologies Inc.), which has no cross-reactivity with mouse SPARC (unpublished data and ref. 45), overnight at $4^{\circ} \mathrm{C}$ and immunoprecipitated with Protein G Sepharose beads (Sigma-Aldrich) at $4^{\circ} \mathrm{C}$ for 4 hours and washed 5 times with lysis buffer. The beads were boiled in Laemmli buffer and centrifuged at $12,000 \mathrm{~g}$ for 10 seconds. The proteins were resolved by SDS-PAGE (10\% gel) under reducing conditions and electrotransferred onto a PVDF membrane and processed as previously described (44).

Immunohistochemistry. Paraffin sections of human colorectal cancers or normal colon were kindly provided by Maximo Loda (Dana Farber Cancer Institute) and David A. Owen (University of British Columbia). Tumors recovered from animal xenografts were similarly processed for immunohistochemistry following fixation in 10\% formalin. Immunoperoxidase staining was performed as previously described (46). Antibodies to SPARC $(4.0 \mu \mathrm{g} / \mathrm{ml}$; Haematologic Technologies Inc.), Ki-67 $(0.2 \mu \mathrm{g} / \mathrm{ml}$; Oncogene Research Products), CD-34 (0.2 $\mu \mathrm{g} / \mathrm{ml}$; DakoCytomation), VEGF (4.0 $\mu \mathrm{g} / \mathrm{ml}$; Santa Cruz Biotechnology Inc.), collagen IV $(1 \mu \mathrm{g} / \mathrm{ml}$; Chemicon International), and laminin ( $1 \mu \mathrm{g} / \mathrm{ml}$; Novotec) were used. We counted the number of Ki-67-positive nuclei per high-power field $(\times 400)$ in order to determine the differences in cell proliferation between the treatment groups $(n=4)$. Similarly, we counted the number of blood vessels per low-power field $(\times 100)$ identified following staining with CD34 antibodies in order to determine the effect of SPARC on blood vessel formation $(n=4)$.

Statistical analysis. Statistical difference between groups was determined by ANOVA followed by post-hoc comparison with Student's $t$ test. $P<0.05$ was considered statistically significant.

\section{Acknowledgments}

We thank M. Loda for providing colorectal cancer tissues for histology and help with immunohistochemistry. The authors are also very grateful to Beverley Thomas (British Columbia Cancer Agency, Vancouver, British Columbia, Canada) for her help with immunohistochemistry. This work was supported by grants from the Canadian Association of Gastroenterology and the Canadian Institutes of Health Research (to I.T. Tai).

Received for publication August 10, 2004, and accepted in revised form April 5, 2005.

Address correspondence to: Isabella T. Tai, University of British Columbia, Division of Gastroenterology, 100-2647 Willow Street, Vancouver, British Columbia V5Z 3P1, Canada. Phone: (604) 875 5039; Fax: (604) 675-8178; E-mail: itai@bcgsc.ca. 
1. de las Alas, M.M., Aebi, S., Fink, D., Howell, S.B., and Los, G. 1997. Loss of DNA mismatch repair: effects on the rate of mutation to drug resistance. J. Natl. Cancer Inst. 89:1537-1541.

2. Tang, R., et al. 2004. p53 is an independent pretreatment markers for long-term survival in stage II and III colorectal cancers: an analysis of interaction between genetic markers and fluorouracilbased adjuvant therapy. Cancer Lett. 210:101-109.

3. Ahnen, D.J., et al. 1998. Ki-ras mutation and p53 overexpression predict the clinical behavior of colorectal cancer: a Southwest Oncology Group study. Cancer Res. 58:1149-1158.

4. Bunz, F., et al. 1998. Requirement for p53 and p21 to sustain G2 arrest after DNA damage. Science. 282:1497-1501.

5. Bunz, F., et al. 1999. Disruption of p53 in human cancer cells alters the responses to therapeutic agents. J. Clin. Invest. 104:263-269.

6. Waldman, T., Lengauer, C., Kinzler, K.W., and Vogelstein, B. 1996. Uncoupling of S phase and mitosis induced by anticancer agents in cells lacking p21. Nature. 381:713-716.

7. Johnston, P.G., et al. 1995. Thymidylate synthase gene and protein expression correlate and are associated with response to 5 -fluorouracil in human colorectal and gastric tumors. Cancer Res. 55:1407-1412.

8. Edler, D., et al. 2002. Thymidylate synthase expression in colorectal cancer: a prognostic and predictive marker of benefit from adjuvant fluorouracilbased chemotherapy. J. Clin. Oncol. 20:1721-1728.

9. Edler, D., et al. 2000. Immunohistochemically detected thymidylate synthase in colorectal cancer: an independent prognostic factor of survival. Clin. Cancer Res. 6:488-492.

10. Takebe, N., et al. 2001. Retroviral transduction of human dihydropyrimidine dehydrogenase cDNA confers resistance to 5-fluorouracil in murine hematopoietic progenitor cells and human CD34+enriched peripheral blood progenitor cells. Cancer Gene Ther. 8:966-973.

11. Salonga, D., et al. 2000. Colorectal tumors responding to 5-fluorouracil have low gene expression levels of dihydropyrimidine dehydrogenase, thymidylate synthase, and thymidine phosphorylase. Clin. Cancer Res. 6:1322-1327.

12. Douillard, J.Y., et al. 2000. Irinotecan combined with fluorouracil compared with fluorouracil alone as first-line treatment for metastatic colorectal cancer: a multicentre randomised trial. [erratum 2000, 355:1372]. Lancet. 355:1041-1047.

13. Giacchetti, S., et al. 2000. Phase III multicenter randomized trial of oxaliplatin added to chronomodulated fluorouracil-leucovorin as first-line treatment of metastatic colorectal cancer. J. Clin. Oncol. 18:136-147.

14. Candeil, L., et al. 2004. ABCG2 overexpression in colon cancer cells resistant to SN38 and in irinotecan-treated metastases. Int. J. Cancer. 109:848-854.

15. Shirota, Y., et al. 2001. ERCC1 and thymidylate synthase mRNA levels predict survival for colorectal cancer patients receiving combination oxaliplatin and fluorouracil chemotherapy. J. Clin. Oncol. 19:4298-4304.

16. Damjanovski, S., Huynh, M.H., Motamed, K. Sage, E.H., and Ringuette, M. 1998. Regulation of
SPARC expression during early Xenopus development: evolutionary divergence and conservation of DNA regulatory elements between amphibians and mammals. Dev. Genes Evol. 207:453-461.

17. Martinek, N., Zou, R., Berg, M., Sodek, J., and Ringuette, M. 2002. Evolutionary conservation and association of SPARC with the basal lamina in Drosophila. Dev. Genes Evol. 212:124-133.

18. Termine, J.D., et al. 1981. Osteonectin, a bonespecific protein linking mineral to collagen. Cell. 26:99-105.

19. Tremble, P.M., Lane, T.F., Sage, E.H., and Werb, Z. 1993. SPARC, a secreted protein associated with morphogenesis and tissue remodeling, induces expression of metalloproteinases in fibroblasts through a novel extracellular matrix-dependent pathway. J. Cell Biol. 121:1433-1444.

20. Sage, H., Vernon, R.B., Funk, S.E., Everitt, E.A., and Angello, J. 1989. SPARC, a secreted protein associated with cellular proliferation, inhibits cell spreading in vitro and exhibits $\mathrm{Ca}+2$-dependent binding to the extracellular matrix. J. Cell Biol. 109:341-356

21. Hasselaar, P., and Sage, E.H. 1992. SPARC antagonizes the effect of basic fibroblast growth factor on the migration of bovine aortic endothelial cells. J. Cell. Biochem. 49:272-283.

22. Motamed, K., and Sage, E.H. 1997. Regulation of vascular morphogenesis by the matricellular protein SPARC. Kidney Int. 51:1383-1387.

23. Damjanovski, S., Karp, X., Funk, S., Sage, E.H., and Ringuette, M.J. 1997. Ectopic expression of SPARC in Xenopus embryos interferes with tissue morphogenesis: identification of a bioactive sequence in the C-terminal EF hand. J. Histochem. Cytochem. 45:643-655.

24. Kupprion, C., Motamed, K., and Sage, E.H. 1998. SPARC (BM-40, osteonectin) inhibits the mitogenic effect of vascular endothelial growth factor on microvascular endothelial cells. J. Biol. Chem. 273:29635-29640.

25. Vajkoczy, P., et al. 2000. Targeting angiogenesis inhibits tumor infiltration and expression of the pro-invasive protein SPARC. Int. J. Cancer. 87:261-268.

26. Francki, A., et al. 1999. SPARC regulates the expression of collagen type I and transforming growth factor-beta 1 in mesangial cells. J. Biol. Chem. 274:32145-32152.

27. Schiemann, B.J., Neil, J.R., and Schiemann, W.P. 2003. SPARC inhibits epithelial cell proliferation in part through stimulation of the transforming growth factor-beta-signaling system. Mol. Biol. Cell. 14:3977-3988

28. Francki, A., et al. 2003. SPARC regulates cell cycle progression in mesangial cells via its inhibition of IGF-dependent signaling. J. Cell. Biochem. 88:802-811.

29. Rempel, S.A., Golembieski, W.A., Fisher, J.L., Maile, M., and Nakeff, A. 2001. SPARC modulates cell growth, attachment and migration of U87 glioma cells on brain extracellular matrix proteins. J. Neu rooncol. 53:149-160.

30. Yiu, G.K., et al. 2001. SPARC (secreted protein acidic and rich in cysteine) induces apoptosis in ovarian cancer cells. Am. J. Pathol. 159:609-622.

31. Schultz, C., Lemke, N., Ge, S., Golembieski, W.A., and Rempel, S.A. 2002. Secreted protein acidic and rich in cysteine promotes glioma invasion and delays tumor growth in vivo. Cancer Res. 62:6270-6277.

32. Porter, P.L., Sage, E.H., Lane, T.F., Funk, S.E., and Gown, A.M. 1995. Distribution of SPARC in normal and neoplastic human tissue. J. Histochem. Cytochem. 43:791-800

33. Chlenski, A., et al. 2002. SPARC is a key Schwannian-derived inhibitor controlling neuroblastoma tumor angiogenesis. Cancer Res. 62:7357-7363.

34. Brekken, R.A., et al. 2003. Enhanced growth of tumors in SPARC null mice is associated with changes in the ECM. J. Clin. Invest. 111:487-495. doi:10.1172/JCI200316804.

35. Puolakkainen, P.A., Brekken, R.A., Muneer, S., and Sage, E.H. 2004. Enhanced growth of pancreatic tumors in SPARC-null mice is associated with decreased deposition of extracellular matrix and reduced tumor cell apoptosis. Mol. Cancer Res. 2:215-224.

36. Abeysinghe, H.R., et al. 2003. THY1 expression is associated with tumor suppression of human ovarian cancer. Cancer Genet. Cytogenet. 143:125-132.

37. Funk, S.E., and Sage, E.H. 1991. The Ca2(+)-binding glycoprotein SPARC modulates cell cycle progression in bovine aortic endothelial cells. Proc. Natl. Acad. Sci. U. S. A. 88:2648-2652.

38. Motamed, K., and Sage, E.H. 1998. SPARC inhibits endothelial cell adhesion but not proliferation through a tyrosine phosphorylation-dependent pathway. J. Cell. Biochem. 70:543-552.

39. Raines, E.W., Lane, T.F., Iruela-Arispe, M.L., Ross, R., and Sage, E.H. 1992. The extracellular glycoprotein SPARC interacts with platelet-derived growth factor (PDGF)-AB and $-\mathrm{BB}$ and inhibits the binding of PDGF to its receptors. Proc. Natl. Acad. Sci. U. S. A. 89:1281-1285.

40. Motamed, K., et al. 2002. Inhibition of PDGFstimulated and matrix-mediated proliferation of human vascular smooth muscle cells by SPARC is independent of changes in cell shape or cyclindependent kinase inhibitors. J. Cell. Biochem. 84:759-771.

41. Wagner, H.E., et al. 1990. Characterization of the tumorigenic and metastatic potential of a poorly differentiated human colon cancer cell line. Invasion Metastasis. 10:253-266.

42. Li, C., and Hung Wong, W. 2001. Model-based analysis of oligonucleotide arrays: model validation, design issues and standard error application. Genome Biol. 2:research0032.1-research0032.11.

43. Tai, T.C., Claycomb, R., Her, S., Bloom, A.K., and Wong, D.L. 2002. Glucocorticoid responsiveness of the rat phenylethanolamine $\mathrm{N}$-methyltransferase gene. Mol. Pharmacol. 61:1385-1392.

44. Sun, Y., et al. 1999. Molecular cloning and characterization of human trabeculin-alpha, a giant protein defining a new family of actin-binding proteins. J. Biol. Chem. 274:33522-33530.

45. Yan, Q., Weaver, M., Perdue, N., and Sage, E.H. 2005. Matricellular protein SPARC is translocated to the nuclei of immortalized murine lens epithelial cells. J. Cell. Physiol. 203:286-294.

46. Signoretti, S., et al. 2000. p63 is a prostate basal cell marker and is required for prostate development. Am. J. Pathol. 157:1769-1775. 